\title{
Bringing Conservation to Cities: Lessons from Building the Detroit River International Wildlife Refuge
}

\section{Iqbal $\mathbf{U}^{*}$}

History Programme, Faculty of Social Sciences and Humanities, National University of Malaysia, Malaysia

*Corresponding author: Iqbal U, History Programme, Faculty of Social Sciences and Humanities, National University of Malaysia, UKM 43650, Bangi Selangor, Malaysia, Tel: 60389215555; E-mail: uqbah@siswa.ukm.edu.my

Received date: January 12, 2016; Accepted date: February 11, 2016; Published date: February 17, 2016

Copyright: (c) 2016 Iqbal U. This is an open-access article distributed under the terms of the Creative Commons Attribution License, which permits unrestricted use, distribution, and reproduction in any medium, provided the original author and source are credited.

Keywords: Detroit River; Ecosystem; International wildlife; Global community

\section{Commentary}

The Aquatic Ecosystem Health and Management Society (AEHMS) publish both a primary international journal, Aquatic Ecosystem Health and Management, and peer reviewed books under the banner of the Eco vision World Monograph Series. The selection process for the Eco vision books is stringent. Since its establishment in 1989, the AEHMS via its journal and book Series, has encouraged and promoted integrated, Eco systemic, and holistic initiatives for the protection and conservation of global aquatic resources. John Hartig [1] in this monograph has provided an outstanding example of fulfilling this mission. This is the second title which John Hartig chose to publish as a part of the Eco-vision Series. In 2010, his book, Burning Rivers: Revival of Four Urban-Industrial Rivers that Caught on Fire won the Green Book Scientific Category Award in 2011.

This monograph tells the story of how innovative partnerships are making nature part of everyday urban life in the automobile capitals of the United States and Canada in an effort to inspire and develop the next generation of conservationists in urban areas, because that is where most people on our planet live. First, it provides a practical example of how sound science is being used as the foundation for ecosystem-based management of the Detroit River.

International Wildlife Refuge, Second it is an excellent example of strengthening the science-policy linkage. Finally, this book provides unique insights and important lessons learned in both scientifically defining the concept of aquatic ecosystem health and in testing and evaluating the efficacy of ecosystem-based approaches to management of aquatic ecosystems on a global scale. For those interested in ecosystem-based management of aquatic ecosystems, particularly in cities, and in bringing conservation to cities worldwide, this monograph is a must read. Aquatic Ecosystem Health and Management Society are honored to include this monograph in its Eco vision World Monograph Series. This book will be a milestone ecosystem-based publication beneficial to researchers, managers and students dedicated to ecological protection and conservation.

It may seem like a paradox to build an international wildlife refuge in such a major metropolitan area that is part of the industrial heartland and the "rust belt," but it really isn't and readers may be pleasantly surprised to learn why and how it is being done. That is the purpose and surprise of this book to tell the compelling story of building North America's only international wildlife refuge in the industrial heartland of the United States and Canada, to share the important lessons learned about how it is being done in an effort to encourage more conservation initiatives in cities throughout the world, and to help inspire and develop the next generation of conservationists that must be developed with increasing frequency in major metropolitan areas because that is where most people on our planet live. Defining this need was strategically addressed in a multistakeholder process for the United States-Canadian cooperation for conservation efforts in and along the Detroit River. The idea was to clearly define a vision, without ambiguity, so that the United States and Canadian stakeholders were working toward the same purpose and had the same expectations. Admittedly, at first it was a little "fuzzy." The United States and Canadian scientists, natural resource managers, nongovernmental organization representatives, and concerned citizens knew that they needed to work together. However, to bring stakeholders from two countries together to reach agreement on a clear and shared vision is no simple task.

Based on the evidence presented in the previous nine chapters, the Detroit River International Wildlife Refuge can be viewed as a successful experiment in conserving continentally-significant fish and wildlife in a major urban industrial area and in helping make nature experiences part of everyday urban life. However, there are many ways and means of fostering conservation in urban areas. One of the goals of this book is to share lessons learned from this experiment of developing and building the Detroit River International Wildlife Refuge. There are ten lessons learned about how this urban wildlife refuge has, thus far, been molded, fashioned, and formed in an effort to conserve continentally-significant wildlife, while making nature experiences part of everyday urban life to help develop a conservation ethic. All lessons may not be applicable to all urban areas and no priority ranking is intended in the numbering scheme. It is hoped that these lessons will help encourage more urban conservation initiatives throughout the world.

The percentage of people in the world living in urban areas has increased from $29 \%$ in 1950 to $49 \%$ in 2007 and is projected to increase to $60 \%$ by 2030 . Today, approximately $80 \%$ of all people in the United States and Canada live in urban areas. Most urban residents are disconnected from the natural world. As a global community, we cannot afford to allow this disconnection to continue. In addition, urban areas are places where most biologists, conservation agencies, and conservationists have historically shied away from. This compounds the problem of bringing conservation to urban areas and of helping develop the next generation of conservationists in urban areas because that is where most of the people on our planet live. There is no doubt that urban refuges and other urban conservation initiatives have the potential to make a significant impact on developing the next generation of conservationists. Urban areas also provide unique opportunities to form public-private partnerships and to leverage resources for conservation. Indeed, that is precisely what is happening at the Detroit River International Wildlife Refuge that has worked with 
Citation: Iqbal U (2016) Bringing Conservation to Cities: Lessons from Building the Detroit River International Wildlife Refuge. Arts Social Sci J S2: S2-004. doi:10.4172/2151-6200.S2-004

Page 2 of 2

over 300 public and private organizations, and leveraged over $\$ 43$ million for conservation projects since 2001 . Today, we stand at a new urban conservation frontier, one that has numerous challenges and opportunities. We need to commit to exploring this frontier and charting a course that brings conservation into urban areas in a fashion that makes nature experiences part of everyday urban life. As a global community, we cannot afford to fail.

\section{References}

1. (2014) Aquatic Ecosystem Health and Management Society, Ontario p: 251.

This article was originally published in a special issue, entitled: "Library sciences", Edited by Chang'ach JK, Department of Educational Foundations, Moi University, Kenya 